\title{
Study on English teaching model based on ability progression
}

\author{
Xiong Shengqi, Zeng Wenjie
}

\author{
Nanchang Institute of Science \& Technology, Nanchang 330108, China
}

\section{Key words: traditional teaching; English teaching; ability progression}

\begin{abstract}
With the accelerated pace of reform, the traditional English teaching model has been unable to meet the needs of the new era. In this paper, an English teaching model based on competence progressive is put forward by analyzing the disadvantages of the traditional English teaching mode, combining with the characteristics of English teaching. The practice shows that, this model creates a target language learning environment for students, so that students get a more comprehensive knowledge, which can improve and mobilize the students' learning enthusiasm, creativity, teamwork ability and practical ability.
\end{abstract}

\section{Introduction}

With the development of economic globalization and Internet technology, English has become a universal language. As a basic language tool, English plays an important role in international communication. Therefore, it has been an important task for colleges and universities to cultivate high-quality applied English talents. However, due to the promotion of curriculum reform is not enough, College English is still bound by the traditional teaching mode to a certain extent, the students are often passive receiving knowledge, lack of autonomous learning training. The following questions will be studied in this paper: how to combine the ability progressive teaching with English, through gradual reform and innovation, to solve the problems in learning English, to improve students' professional quality, to enhance the quality of personnel training, and to form a distinctive teaching mode.

\section{The teaching system of ability progressive model}

The ability progressive mode of teaching mode is to meet the needs of society, take the cultivation of applied talents as the focus of the work, and strive to improve the professional quality of students, enhance the overall quality of personnel training, and form a unique distinctive culture mode. The teaching method of the model mainly includes three aspects: the construction of English quality standard system, building the training strategy of the ability progressive improvement, and the construction of English quality training system with progressive ability improvement.

(1) Building English quality standard system

According to the overall English level of college students, in order to improve the English ability of the students in different grades, this paper constructs a professional quality standard system for English majors, including three basic standards: the general English competence, the basic ability of English majors and the advanced application ability of English. We focus on the needs of society, cultivate applied talents as the focus of the work, and strive to improve the professional quality of students, according to the position requirements for English majors as basis, to enhance the quality of personnel training, to build professional quality training course teaching system and the ability progressive improvement of English teaching mode. The establishment of an English teaching 
model with the ability progressive improvement can facilitate the establishment of curriculum and teaching objectives, and provide system standard for the evaluation of students' English quality.

(2) Building the training strategy of the ability progressive improvement

Combining with the needs of the industry and the training objectives of applied innovative talents, we focus on improving the practical ability of students, and determine the progressive learning strategy of " $2+1+1 "$. The training strategy makes a reasonable arrangement for the progressive promotion of English Majors students in the 4 school year, including: (1) In the first and two school year, we should focus on the cultivation of students' English foundation, that is the cultivation of English general competence; (2)In the third school year, we should combine the students' professional interests to shape the basic ability of English majors; (3)In the fourth year, we will focus on the application of innovative and practical teaching arrangements to improve the students' ability to apply advanced English, so that students have the ability to post professional.

(3) The construction of English quality training system with progressive ability improvement

Based on the cultivation of English quality standard system, the training system of English progressive ability, which is based on the classroom and supplemented by the class, is adopted.

(a) Construct the system to improve the overall level of the students' English, establish three platforms, such as the improvement of teachers' ability, the training of students' skills in school and the practice of students' off campus. The purpose of setting up the platform of teachers' ability improvement is to improve the teachers' teaching level and practical ability, to build up the teachers' ability with both ability and political integrity, and to avoid the phenomenon of teachers' lack of ability. The purpose of the establishment of students' skills training platform is to change the students' professional ability from the classroom to the extracurricular, according to the standard system of the English level of the students, then we can carry out a series of targeted training to improve the ability to improve students' overall English skills. The purpose of setting up the platform for students to practice skills is to make students understand the social needs and the development of the industry, to enhance students' practical work experience, to provide students with a sense of urgency, to provide learning motivation.

(b) The construction of students' Extracurricular English quality training guidance system, paying attention to students' practice teaching content. We adopt group mentoring, start grouping with mentors from freshmen, according to the quality standard of English syllabus, combine the students' autonomous learning with teachers' proper guidance, through assignments, projects or organizes the student to participate in the English competition, Have a planned, purposeful, hierarchical guidance of students to complete the task of learning, and improve students' own quality. In addition, the tutor is responsible for the career planning of each group of students in the future direction of work, to achieve the normalization of students' English application ability and work skills training.

(c) Forming the circulation mechanism of ability progressive training from simple to complex, from low to high. The first layer of the students' general ability is the foundation to make students possess the necessary professional basic skills; second level English majors basic ability of students in relevant professional must have a minimum of third senior level occupation literacy; application ability of English is to improve students' employment competitiveness and innovation ability, and work for the students looking for jobs and lay a solid foundation, so as to realize the comprehensive cultivation of students of three levels of ability in English. 


\section{Study on English teaching model based on ability progression}

The design of ability progressive English teaching model. In the process of English teaching, students tend to be afraid of speaking, words can not remember and can not continue to learn English and other issues. In order to change this problem and get good teaching effect, we should pay attention to the choice of teaching mode. In the custom of teaching mode and teaching syllabus, we should choose clear objectives, tasks appropriate and practical work related teaching project in the class as an exercise, according to the research on the enterprise, in accordance with the conditions of the project, improve the students' English listening, speaking, reading and writing ability. At the same time, teachers should be encouraged to use English Teaching in order to improve the current English learning environment.

Implementation process. (1) According to the development of the English teaching quality standard system, the ability to improve the progressive training strategy and the ability to improve the progressive type of English training mechanism, the development of teaching programs and practical projects under the task of the book.

(2) According to the project practice book distribution class teachers, 7 to 8 students should be divided into a learning team, teachers give students simple explanations of project tasks, and then together with the student project decomposition, guide the students to summarize key points, access to relevant literature, ready to work.

(3) Team members work according to the information and clues. The head of the team is responsible for the project discussion, detail and team cooperation, team members responsible for the collection of their own issues to find out the difficulties, and propose solutions. Team regularly summarize the progress of the team members and the problems encountered, and then organize the team meeting to communicate, we discuss the solution of the problem. For the problem can not be solved, you can ask the instructor. The process of English teaching can be divided into: Distribute the project task book, project analysis, project decomposition and distribution, access to the relevant literature, collect the problem and make the solution to determine the overall project plan. In the process of completion of the project, we should focus on the students to find out and solve problems, guide students to find literature, let the students to apply theoretical knowledge to practice, to study, to stimulate students desire for knowledge, and then improve students' comprehensive quality.

(4) The instructor group will discuss the results of the students, according to the actual completion of the project and the project report to determine the score, and excellent works on display, and finally to improve the summary.

Evaluation assessment. The main basis of the project assessment includes 8 aspects: the process assessment, the completion of the work, the overall quality of the work, excess completion, innovation degree, team coordination, problem-solving skills and project reports. It is not a single evaluation way in the project assessment process (guiding grades are given directly, but teachers), it is a series of comprehensive evaluation results from the beginning of the project to completion, in addition to the evaluation of the results of the evaluation, we should pay more important attention to the whole process of the project the students play. That is to say, the evaluation criteria were transferred from traditional absolute score to relative score, students can participate in the learning achievement score segment, score for their performance in the project, which can greatly stimulate the students' spirit of competition, and improve the enthusiasm of the students. After comprehensive consideration, the final assessment method is shown in table 1. 
Table 1 The final assessment method

\begin{tabular}{|c|c|c|}
\hline Assessment and evaluation & Proportion (\%) & Score content \\
\hline Process assessment & $10 \%$ & Performance display \\
\hline Completion degree & $30 \%$ & Whether to fulfill the requirements of the project \\
\hline Overall quality of works & $10 \%$ & The rationality of project design and feasibility \\
\hline Excess completion & $10 \%$ & $\begin{array}{l}\text { Whether have a reasonable play on the basis of } \\
\text { completion }\end{array}$ \\
\hline Innovation degree & $10 \%$ & Whether the content is innovative \\
\hline Team coordination ability & $10 \%$ & Whether the implementation of process coordination \\
\hline Problem solving skills & $10 \%$ & $\begin{array}{l}\text { Whether the project can be found in the process of } \\
\text { self - Search and solve the problem }\end{array}$ \\
\hline Project Report & $10 \%$ & $\begin{array}{l}\text { The overall design, the experimental results, the } \\
\text { structure of the project report and the standardization } \\
\text { of the document }\end{array}$ \\
\hline
\end{tabular}

\section{Model implementation and result analysis}

Practical application of English teaching mode based on ability progressive, can improve students' interest in learning, teamwork ability, self-learning ability, practical ability and the ability to discover and solve problems, and improve the students' English quality, which can achieve the teaching effect. In order to special evaluate traditional teaching and ability progressive teaching mode, an online activity score has been conducted in a school, the evaluation is mainly divided into five aspects of the content, the content of the full score is 5 points, the results are shown in Table 2 .

Table 2 Comparison of evaluation results

\begin{tabular}{|l|c|c|}
\hline \multicolumn{1}{|c|}{ Score content } & Traditional mode & Ability progressive model \\
\hline $\begin{array}{l}\text { Students' understanding of the content structure and the } \\
\text { mastery of learning methods }\end{array}$ & 3.8 & 4.1 \\
\hline The degree of students' acquisition of curriculum & 3.6 & 4.3 \\
\hline $\begin{array}{l}\text { Whether teachers use a variety of methods to explain } \\
\text { whether the classroom atmosphere is active }\end{array}$ & 3.5 & 4.4 \\
\hline $\begin{array}{l}\text { Whether teachers are good at stimulating students' learning } \\
\text { enthusiasm, clear learning objectives and methods }\end{array}$ & 3.6 & 3.9 \\
\hline $\begin{array}{l}\text { Paying attention to the cultivation of students' innovative } \\
\text { consciousness }\end{array}$ & 3.7 & \\
\hline
\end{tabular}

After adopting the ability progressive teaching model, the students' satisfaction degree of each evaluation index is greatly improved, which makes the College English class more active. For students, the students' knowledge has been improved, the students' desire for knowledge has been stimulated, the comprehensive quality of students has been improved; in terms of teachers, only to carry out practice teaching, optimize the teaching model in the implementation process, improve teaching methods, can improve their teaching level.

\section{Conclusion}

It can creates a target language learning environment for students by the application of ability 
progressive teaching model in College English teaching, paying attention to the needs of society and enterprises in the actual teaching process, according to the specific needs of the establishment of a more comprehensive teaching model, so that students get a more comprehensive knowledge, the mobilization of students' learning enthusiasm, creativity, teamwork ability and practical ability has been improved. After adopting the progressive teaching model, the students' satisfaction degree of each evaluation index is greatly improved, which makes the College English class more active.

\section{Reference}

[1] Xie Xiaohui. The study of Vocational College English teaching model based on professional ability[J]. Contemporary Education Research and Teaching Practice, (2017), p.1-2.

[2] Song Haoyang. Study on the hierarchical and progressive teaching model of tea culture in educational ecology [J]. Tea in Fujian,No.02 , (2017), p.176-177.

[3]Zhu Zhengyue. The design and implementation of the progressive practice system for the specialty of Internet of things application technology [J]. Journal of Anhui Vocational \& Technical College, No.04, (2016): 74-76, 80.

[4] Xu Qinghe. The construction of the mode of Cultivating College Students' entrepreneurial ability based on the gradual progress: a study of local colleges and universities [J]. Journal of Anyang Normal University, No.04, (2016), p.134-137

[5] Wang Yan. Construction of progressive training system of vocational ability in Higher Vocational Education [J]. Education Teaching Forum, No.12, (2015) ,p.226-227.

[6] Cong Shuaishuai. Discussion on the development prospect of the undergraduate curriculum of national folk dance education: a case study of the Dance College of Minzu University of China [J]. Tibetan Art Studies, No.04, (2014), p.53-57.

[7] Zhao Langlang. Application of ESP in College English teaching [J]. Journal of Heilongjiang College of education, No.05 , (2014), p.167-168.

[8] Zhu Xiuzhi, Song Jingying. Study on the cultivation of autonomous learning ability in English teaching [J]. Modern Communication, No.09, (2012), p.236-237.

[9] Su Huiying. The study of the role of teachers and students in senior high school English Teaching under the background of the new curriculum reform [D]. Shandong Normal University, (2012)

[10] Liu Chunzhi, Sun Lili. Research on the hierarchical progressive teaching system based on the improvement of employment ability: a case study of economic and trade major [J]. Modern Education Management, No.01 , (2012), p.79-82.

[11] Zhou Liqin, Li Yingchun, Ye Yuanjian. The exploration and practice of ability progressive teaching reform project -- Application in MCU [J]. Light Industry Science and Technology, No.08, (2011), p.202-203.

[12] Feng Haiyun, Li Chunling. Discussion on the cultivation of students' autonomous learning ability under the theme teaching mode [J]. Science and Technology of West China, Vol.35, (2009), p.93-94. 
[13] Fu Lingfang, Yang Jianding. Study on the autonomous learning ability of College English teaching model based on network multimedia [J]. Foreign Languages and Their Teaching, No.10, (2007), p.36-38. 